\section{Mudanças climáticas nos assentamentos rurais: uma etnografia sobre a experiência de futuro ${ }^{1}$}

Alexsandro Elias Arbarotti ${ }^{2}$ Rodrigo Constante Martins ${ }^{3}$

RESUMo: O objetivo do presente artigo é analisar como as mudanças climáticas são percebidas e impactam o modo de produção e a existência sócio cultural dos assentados rurais da reforma agrária, por meio de um estudo de caso no maior Assentamento do estado de São Paulo. Os dados empíricos foram coletados a partir de trabalhos de campo realizados entre os anos de 2014 e 2017 dentro da perspectiva da história oral. Fora tomado como evento balizador da análise a crise hídrica vivida no estado de São Paulo no ano de 2014, tida como o maior período de estiagem vivido no estado. Os resultados mostraram que esse evento foi tido como a expressão de um processo que é percebido pelos assentados há muito tempo. Segundo os relatos está cada vez mais difícil produzir, pois não é mais possível saber quando vai chover. Esse cenário produz uma situação de incertezas, medos e angústias em relação ao futuro pessoal e do planeta. A verificação desse ambiente de ausência de futuro é tomada no artigo como um elemento chave para a construção de uma nova ordem social e ambiental que leve em conta todos os viventes.

PalaVRas-ChaVe: Assentamentos Rurais; Mudanças Climáticas; Questão Ambiental; Sensibilidade Ambiental; Ruralidades.

ABSTRACT: The objective of this article is to analyze how climate change is perceived and impact the mode of production and socio - cultural existence of the rural settlers of agrarian reform, through a case study in the largest Settlement in the state of. Empirical data were collected from field studies conducted between 2014 and 2017 from the perspective of oral history. The water crisis experienced in the state of São Paulo in the year of 2014, taken as the largest period of drought experienced in the state, had been taken as the main event of the analysis. The results showed that this event was seen as the expression of a process that has long been perceived by the settlers. According to the reports it is increasingly difficult to produce, because it is no longer possible to know when it will rain. This scenario produces a situation of uncertainties, fears and anguish about the personal and planetary future. The verification of this environment of absence of future is taken in the article as a key element for the construction of a new social and environmental order that takes into account all living.

'Esta pesquisa contou com apoios da Fundação de Amparo à Pesquisa do Estado de São Paulo (FAPESP), da Coordenação de Aperfeiçoamento de Pessoal de Nível Superior (CAPES) e do Conselho Nacional de Pesquisa e Desenvolvimento Tecnológico (CNPq).

${ }^{2}$ Graduação em Ciencias Sociais na Universidade Estadual Paulista - Campus Marília, Mestrado e Doutorado pelo Programa ${ }^{2}$ Graduação em Ciencias Sociais na Universidade Estadual Paulista - Campus Marilia, Mestrado e Doutorado pelo Programa
de Pós-Graduação em Sociologia da Universidade Federal de São Carlos, com período sanduiche na Universidade de Paris Nanterre. Atualmente pós-doutorando no Laboratoire Eau, Environnement et Systèmes Urbains (Leesu) - École des Ponts Paris Tech. E-mail: arbarotti@gmail.com

${ }^{3}$ Professor do Departamento de Sociologia e do Programa de Pós-Graduação em Sociologia da Universidade Federal de São Carlos. Bolsista Produtividade em Pesquisa do CNPq.E-Mail: constantemartins@gmail.com

\section{INTRODUÇão}

O $4^{\circ}$ relatório do IPCC, lançado em 2007, fazia o prognóstico de que possivelmente até o fim deste século o gelo do Ártico poderá desaparecer. Já o $5^{\circ}$ relatório, de 2013, coloca como provável a quase total ausência de gelo marinho no Ártico até meados deste século. Isso demonstra a velocidade das mudanças climáticas e a dificuldade de se realizar qualquer prognóstico. Esse cenário, abre um quadro de incertezas quanto ao futuro, e deixa uma única garantia, como afirmam Danowski e Viveiros de Castro (2014a, p.23), parafraseando o Manifesto Comunista de Karl Marx: "Tudo que é sólido - a começar pelo gelo mais antigo da Terra - desmancha no mar". E para continuar nas paráfrases de Marx, François L'Yvonnet, no prefácio do livro de Anders (2007, p.10. Tradução nossa) diz: "Os filósofos não fizeram que interpretar e transformar o mundo. Doravante, é importante conservá-1o ${ }^{4}$ ”.

De fato, segundo estudo realizado por pesquisadores das universidades de Stanford, Princeton e Berkeley, o número de desaparecimento de animais vertebrados está em um ritmo 114 vezes mais rápido que o normal. Ou seja, enquanto nas últimas décadas o número de humanos quase dobrou, o de insetos $\mathrm{e}$ de crustáceos diminuiu cerca de $45 \%$. Isso significa, segundo o estudo, que cerca de 322 espécies desapareceram nos últimos cinco séculos (PLIMM et al, 2014).

Algo confirmado pelo relatório divulgado no dia seis de maio de 2019 pela Plataforma Intergovernamental sobre Biodiversidade e Serviços Ecossistêmicos das Nações Unidas, que realizou o mais completo estudo sobre a conservação da natureza dos últimos 50 anos. Segundo o relatório estamos vivendo um período de destruição em massa da biodiversidade sem precedentes na história e que, por isso, mais de 1 milhão de seres vivos estão ameaçados de extinção. Segundo Manuela Carneiro da Cunha, que participou da cúpula trazendo o conhecimento dos povos indígenas sobre o tema, é urgente uma mudança no modo de fazer comércio e de explorar os recursos para fazer face a essa situação. Uma mudança estrutural e profunda para tentarmos evitar o pior (G1 NATUREZA, 2019).

Esse cenário ocorre porque a moderna sociedade capitalista se organiza como um sistema dependente do crescimento econômico permanente para continuar a existir. Harari (2016) observa que a falta de crescimento da economia, no capitalismo, significa seu colapso. E é essa base que faz com que o capitalismo seja um sistema perigoso para o planeta e para as próprias pessoas, pois esse crescimento está baseado na extração de minérios, de petróleo, da exploração da força de trabalho ${ }^{4}$ No original: « Les philosophes n'ont fait qu'interpréter et transformer le monde. Désormais, il importe de le conserver ». 
humana e da energia da natureza (LEFF, 2005). Assim, todas as vezes que se fala em busca de crescimento econômico se esquece de dizer que a solução dos problemas de crescimento se dá, no modelo capitalista, por meio do acúmulo de desigualdades sociais, poluição, envenenamento por pesticidas, esgotamento de recursos, baixa dos lençóis freáticos, uso de energias poluentes, extração de petróleo e etc. (STENGERS, 2013).

Fatores que interferem, diretamente, nos processos biofísicos do "Sistema Terra", provocando acidificação dos oceanos, depleção do ozônio estratosférico, perda da diversidade, interferência nos ciclos globais de nitrogênio e fósforo, mudança no uso do solo e outras coisas mais que, segundo Danowiski e Viveiros de Castro (2014a), não permitirão em um futuro próximo a vida de diversas espécies, inclusive a humana. Esse modelo de superdesenvolvimento e do crescimento a todo custo, portanto, está findando com o planeta.

Segundo Ceceña (2013), isso ocorre pelo fato de vivermos um período de produção industrial exagerada, que atrapalha o equilíbrio longamente constituído pela natureza. E a interferência nesse equilíbrio, por conta das atividades humanas (antrópicas) apontam para consequências reais de catástrofes e de uma crise no sistema do planeta. Em outras palavras, o fim do mundo, pelo menos como nós o conhecemos (DANOWSKI; VIVEIROS DE CASTRO, 2014a; 2014b).

Entretanto, não são somente os dados e pesquisas científicas que dão conta dessa transformação, e da consequente sensação de não futuro, uma vez que comunidades tradicionais e camponeses já apontam para a percepção da alteração climática em seus cotidianos de caça, pesca e plantio, com a aguda mudança nos hábitos dos animais, dos regimes de chuvas e do desenvolvimento das plantas. Assim, se um grupo de pessoas continua agindo como se nada estivesse acontecendo, para muitas outras pessoas e grupos sociais, as mudanças climáticas já são um fato, uma experiência concreta e cotidiana, como pode-se observar na fala a seguir:

\section{Entrevistador: E a senhora acha que vai chover hoje?}

Dona Aparecida: Não está com cara de chuva não. Apesar que hoje em dia está tudo mudado. O tempo está igual à gente. Naquele tempo [de quando ela era jovem], eu fui criada na roça com meu pai, chovia dezembro, janeiro, fevereiro e março e depois parava [a chuva]. Ai ele sabia o dia certo de plantar: - "Vamos plantar que vai chover!" Hoje não, ninguém sabe o dia que vai chover, está tudo mudado, como a gente. Do jeito que não está chovendo uma hora não vai ter nem a água dos poços que usam para irrigar as plantas.

Era agosto de 2015, quando Dona Aparecida, 82 anos, da varanda da sua casa, em um dos lotes do Assentamento Reunidas, em Promissão (São Paulo), proferiu essas palavras em tom de lamentação. E o evento que baliza este momento é a crise hídrica vivida no estado de São Paulo no ano de 2013, agravada em 2014 e que se arrastou por 2015, tido como o maior período de estiagem vivido no estado. Seca que impactou os reservatórios de abastecimento das cidades e afetou a produção agrícola. No assentamento como um todo o clima era de desolação, preocupação e medo, pois muitas famílias estavam perdendo toda as suas produções e a água dos poços mal dava para o abastecimento doméstico.

Todos esses sentimentos não eram oriundos somente do evento da seca, mais sim da percepção de que estava tudo mudado e já havia algum tempo. Dona Aparecida, que no momento da entrevista tinha oitenta e dois anos, trabalhou grande parte da sua vida na lida do campo com seus familiares. A partir da sua experiência de vida como trabalhadora rural e camponesa ela rememora um tempo em que o clima era conhecido e ordenado, assim como as pessoas que ela conhecia. Mas o correr da vida embaralhou tudo, as pessoas mudaram, o clima mudou e não é mais possível se confiar nem nas pessoas e nem no clima.

Em razão dessa alteração no clima, o agricultor experimenta uma existência ameaçada, pois ele já não tem mais a segurança de dizer como o pai de Dona Aparecida dizia: "Vamos plantar que vai chover!'. O que resta hoje ao agricultor é arriscar, colocar as sementes na terra sem saber se elas vão "vingar", se o tempo vai ajudar, ou elaborar outro tipo de estratégia como a irrigação, com água retirada do poço. Entretanto, Dona Aparecida também tem dúvidas sobre até quando isso poderá ser feito, pois como a chuva tem diminuído, as águas desses poços também estão secando. Ela diz isso não por mera especulação, mas por experiência, pois no lote onde mora o poço que vertia sete mil litros de água por hora, hoje verte somente 500 litros, o que impactou diretamente a produção de legumes que seus netos possuíam no lote.

Nesse contexto, a proposta do presente artigo é tratar como as mudanças climáticas são sentidas, vividas e experimentadas por esse grupo de assentados do Assentamento Reunidas. Além da presente introdução, o artigo conta com três tópicos. O primeiro tópico é dedicado a perceber como essas mudanças são sentidas dentro dos processos produtivos dos assentados. Em seguida, no segundo tópico, serão abordados os impactos dessas mudanças na estrutura de sentimentos desses assentados, ou seja, o quanto esse cenário é responsável por perturbações não somente materiais, mas subjetivas e existenciais. Se observará como essas 
angustias levam à descrença enquanto ao futuro e ao surgimento de discursos sobre o fim do mundo - ou, pelo menos, do mundo tal como se conhece hoje. Em seguida serão reunidas observações finais e indícios para que, sob a ótica dos assentados, se possa pensar na construção de um mundo social e ambientalmente inclusivo.

Os dados empíricos presentes no texto são resultado de pesquisa de campo qualitativa realizada no Assentamento Reunidas entre os anos de 2014 e 2017. Nesse período foram feitas incursões no campo em que foram realizadas visitas a quinze lotes, com o objetivo de estabelecer uma aproximação com os assentados. A partir de meados de 2015 foram realizadas coletas de depoimentos com 21 assentados e assentadas, por meio de roteiros semiestruturados, dentro da perspectiva da história oral. Como as incursões a campo tinham por objetivo adentrar na vida social e cultural dos assentados, o uso do caderno de campo foi imprescindível para o registro de conversas, situações e impressões ocorridas no cotidiano.

\section{Agricultura em TEMPOS DE INCERTEZAS}

O Assentamento Reunidas é o maior assentamento do estado, com área total de pouco mais de 17 mil hectares. Deste total, cerca de 12 mil hectares são destinados à produção e os outros 5 mil hectares perfazem áreas de preservação ambiental. $\mathrm{O}$ assentamento está dividido em 629 lotes com média de pouco mais de 19 hectares, alocados em dez agrovilas. Essas agrovilas foram elaboradas de modo a facilitar a organização das famílias e a convivência. Todas contam com uma igreja, um campo de futebol e um salão para reuniões e atividades da comunidade (ARBAROTTI, 2018).

Logo no início do Assentamento Reunidas, quando as famílias foram assentadas após um longo processo de luta, que perdurou de 1983 a 1987, algumas famílias elaboraram estratégias de irrigação para efetuar seus primeiros cultivares, mesmo sem a disponibilidade de energia elétrica (ARBAROTTI, 2018, NORDER, 2004, BORGES, 1997). Outras famílias, entretanto, preferiram não adotar esse tipo de estratégia produtiva. Como é possível identificar na fala de Carla, 29 anos, a seguir, naquele tempo, o clima era muito bom e os agricultores podiam escolher entre fazer roças com irrigação (na maioria das vezes verduras) ou realizar o plantio de culturas que não precisavam de irrigação, como o milho.

\section{Entrevistador: E como fazia para irrigar na época que tinha "sariu"? Por que não tinha bomba para puxar, vocês puxavam na mão e saiam regando?}

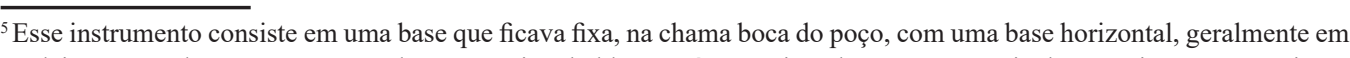
madeira, por onde passava-se a corda que erguia o balde com água, acionado por uma manivela. Esse instrumento visava diminuir o peso do balde. Esse dispositivo é importante, pois alguns poços poderiam chegar a 30 metros de profundidade.
Carla: Mas ai o clima era muito bom, muito bom mesmo, nunca naquele tempo eu ouvi falar que alguém perdeu uma roça de milho. Dava muito milho, só não tinha muito preço, mas era muito linda as roça de milho.

\section{Entrevistador: Aí não precisava regar?}

Carla: Não, era só a data de plantar e a data de colher certinho, a época de colher estava um sol maravilhoso. O pessoal colhia, arroz dava muito bom.

\section{Entrevistador: Então a necessidade de irrigar veio da mudança do clima?}

\section{Carla: Do clima.}

Na fala de Carla vale destacar a frase, "nunca naquele tempo eu ouvi falar que alguém perdeu uma roça de milho". Um tempo pretérito, em que o clima era bom e se podia contar com ele. Nesse sentido, o clima no passado, proporcionava a segurança de que lançar a semente ao chão era sinônimo de uma boa colheita, como fora possível observar na fala de Dona Aparecida, quando esta dizia que seu pai sabia o dia certo para plantar, porque naquele tempo se conhecia o regime das chuvas. O tempo pretérito refere-se, portanto, a um período em que o clima era parceiro no processo produtivo, quase como um compadre com quem poderia se contar para realizar um trabalho difícil na roça. Assim, os agricultores, há algum tempo atrás, conheciam as datas certas em que se realizava a semeadura e o tempo que seria o da colheita.

O clima atual já não é mais o mesmo. O clima não é mais o portador daquilo que $o$ agricultor necessita - a chuva na semeadura e o sol na colheita. Como afirma Stengers $(2013 ; 2015)$, vivemos tempos estranhos, um pouco como se tivéssemos suspensos entre duas histórias. Uma, que é o mundo que conhecemos, marcado pela lei do mercado e do crescimento; e outra, desconhecida, pois não entendemos ainda o que nos espera no futuro. Este ambiente produz o que Benjamin (1989) chamara de espetáculo de uma multidão doentia, que traga poeiras das fábricas, inspira partículas de algodão e se contamina com os venenos usados na produção de obras primas. Contaminação e exploração que produzem também o espetáculo de uma natureza degradada, que começa a dar algumas respostas diante de tanta 
exploração.

E a resposta sentida pelos agricultores é de um clima descontrolado, fora do eixo. Assim, ao contrário do que fora afirmado por Carla, de que ela nunca havia ouvido falar de alguém que tinha perdido uma roça de milho, o contexto agora é de perdas sucessivas de roças, que muitas vezes não chegam nem mesmo a nascer. Conforme afirma Seu Chico 78 anos,, em prosa com seu filho Simão, 41 anos:

Seu Chico: O milho aquele tempo era setembro, outubro, né [para plantar]? Há trinta anos atrás, né? Povo ia lá tentando, né? Até em agosto o povo plantava milho, naquele tempo, plantava e dava bom hein...

\section{Entrevistador: Agora mudou isso, o mês do milho?}

Seu Chico: Agora ninguém, tem que falar a verdade, ninguém tá entendendo..

\section{Simão: Descontrolou.}

Seu Chico: Descontrolou tudo agora. Que nem nós agora plantamos milho em fevereiro, né?

Simão: Março...

Seu Chico: $O$ ano passado mesmo, vou falar uma coisa para você, nós e muitas pessoas perdeu tudo a safra de milho. Teve lugar que nem chegou a nascer uma espiga. Tem mudado muito a chuva.

O que se nota neste diálogo é a percepção de um clima descontrolado e, justamente por isso, um clima que ninguém consegue entender. É muito forte a afirmação de Seu Chico de que ninguém está entendendo mais o que se passa com o clima. Isso porque a profissão de camponês por séculos foi marcada pelo grande domínio das técnicas de plantio e sobretudo um grande conhecimento dos ciclos climáticos que lhe permitiam plantar no momento certo a cultura mais apropriada para aquele período e boas condições para realizar a colheita, como disse Carla, ao contar que naquele tempo no momento da colheita havia um sol maravilhoso.

É muito comum os camponeses atribuírem aos fenômenos climáticos qualidades como chuva boa e sol lindo. Isso demonstra uma ligação com esse fenômenos e, sobretudo, o que significam essas fenômenos para suas vidas. Uma chuva boa vem mansinha e faz bem para a plantação. Uma chuva brava ou feia, destrói toda a plantação, causa enchentes. Um sol maravilhoso ajuda a planta se desenvolver e é bom para a colheita. Um sol bravo mata a plantação e faz sofrer homens, mulheres e animais.

Mas voltando ao contexto da falta de entendimento dos camponeses quando ao clima, esse fato os levam a fazer a agricultura dentro de um sistema de aposta. Um sistema que busca dar uma resposta à falta de compreensão pela mudança dos meses em que se lança as sementes ao solo. Dentro desse contexto de aposta, a boa colheita é incerta. O espaço entre a aposta, semeadura, e o resultado, a colheita, é carregado de angústias e de incertitudes. E essa angústia vem crescendo sistematicamente, pois essas mudanças no sistema climático vem acontecendo de forma tão rápida que os camponeses não estão conseguindo acompanhar. Exemplo flagrante é a fala de Seu Chico, que dizia que os meses de plantio do milho mudaram tanto que atualmente eles plantam em fevereiro, porém, em seguida ele foi corrigido pelo seu filho que disse que na verdade atualmente é em março.

É fato que as mudanças fazem parte da lógica do planeta, porém a velocidade e a amplitude com que essas mudanças estão acontecendo não permitem às populações ligadas aos ciclos climáticos do planeta a se adaptarem de forma satisfatória e a cumprirem com suas atividades profissionais. E por não entenderem mais o clima, a atividade agrícola passa a ser um desafio a ser superado. Foi com uma voz de lamento que Seu Chico disse que ele e muitos outros companheiros haviam perdido todas suas roças de milho no ano de 2014, por conta da seca. E ele ainda precisa que em alguns lugares nem mesmo uma espiga havia nascido. Uma aridez, uma esterilidade que esses camponeses desconheciam, no tempo em que o clima era conhecido.

Seu Chico termina sua fala dizendo que a chuva tem mudado muito, ou seja, essa fala revela a importância para a sua atividade de um ciclo regular e conhecido dos regimes de chuvas. Nesse sentido é possível perceber que a chuva é vista como elemento central no processo de produção para os camponeses. E justamente o descontrole do clima, ou melhor, a falta de conhecimento e compreensão desse regime de chuvas atual é que leva à perda das lavouras e impede que as plantações nasçam, segundo a fala de Seu Chico e Simão.

E a dificuldade de se compreender esse regime de chuvas atual deve-se ao fato dele mudar em uma velocidade muito grande, como já visto. Porém, a fala de seu José, 66 anos, a seguir, ajuda a precisar um pouco mais a velocidade e a percepção das mudanças no Assentamento em um curto espaço de tempo:

Seu José: Porque quando nós chegamos aqui no comecinho em 
2001/2005, chovia que essas caixa de água [curvas de nível que evita o assoreamento do solo], tem 7 no meu sítio, todas lotavam [de água]. Dava até paturi, esses passarinho aqui. [...] Depois nunca mais encheu, até hoje, a chuva tá vindo mais parcialmente, mas tá vindo pouca, só que ela tá vindo, mas antes chovia assim direto, 15 , 20 dias direto. Lotava essas caixa de água tudo aí, agora...

Na fala, é possível perceber a mudança nos regimes de chuvas em um espaço de tempo muito pequeno, pois a sua referência foi de 2001 a 2005. Com isso, em pouco mais de 10 anos já são significativas as mudanças percebidas. E essas mudanças são percebidas levando em conta os elementos geográficos que fazem parte do lote. Os parâmetros usados para mensurar as transformações nos regimes de chuvas, portanto, não são meras especulações subjetivas, mas sim parâmetros que levam em conta elementos externos, e por que não objetivos, a partir de um método comparativo. Se outrora as caixas de retenção ficavam cheias e hoje elas não enchem mais, significa que a quantidade de chuvas tem sido menor, nos cálculos feitos por Seu José. Os elementos que formulam a sua constatação é o resultado da sua experiência em seu sentido largo, em que os elementos físicos externos compõem a formulação de sua memória e experiência (BENJAMIM, 1989; HALBWACHS, 2006).

As caixas de retenção que há dez anos ficavam repletas de água, a ponto de os passarinhos virem nadar, em 2015 já não enchiam mais. Não enchiam porque a chuva diminuiu. E o fato das chuvas diminuírem não afeta somente as curvas de nível que não ficam mais cheias, mas toca em um outro sistema hídrico, que é a disponibilidade de água dos poços que muitas famílias usam como fonte de água potável e para irrigação de suas plantações. Neste contexto, as famílias do Assentamento, que dependem do poço para a produção e para o uso doméstico, passaram a enfrentar nítida situação de insegurança hídrica. Um drama que é possível perceber nas falas de Lara, 33 anos, e de seu pai, Seu João, 65 anos, que estavam acostumados com um poço que vertia cerca de sete mil litros de água por hora e que quase secou em 2014:

Seu João: Um ano inteirinho de seca, ano passado [2014], foi o ano todinho...

Entrevistador: Primeira vez que baixou assim ou sempre baixa [o poço]?

Seu João: Não, foi a primeira vez. Aí nós limpamos e ramificamos.
Lara: Esse poço abastecia o tanque aqui né, pai?

Seu João: $E$, o tanque

\section{Entrevistador: Esse tanque era pra quê?}

Seu João: Para irrigação.

Entrevistador: E vocês irrigavam o quê?

Seu João: Quiabo, berinjela.

\section{Entrevistador: E o senhor parou com o quiabo?}

Seu João: Parei por causa da falta de água do ano, aí baixou o poço, aí...

\section{Entrevistador: Porque o quiabo se não irrigar, não vai?}

Seu João: Não dá, né.

Lara: Abobrinha tá aí sofreno, mas tá produzindo. A seca foi feia.

O primeiro ponto que merece ser destacado na fala é a precisão feita por Seu João de que foi a primeira vez, desde que ele chegou ao seu lote, há trinta anos, que o poço teve uma baixa tão significativa a ponto de impactar a produção. E nem mesmo a estratégia elaborada pela própria comunidade do Assentamento de ramificar o poço, para acessar maior quantidade de água, é capaz de surtir resultado, como visto na fala ${ }^{6}$. Isso demonstra que essa situação tem levado vários agricultores a terem dificuldades para dar continuidade em suas produções.

E continuando com as falas de Seu João e de Lara, em um outro ponto, é possível perceber que ambos mencionam um tanque que outrora era usado como reserva de água para a irrigação de quiabo, mas que havia sido abandonado por falta de água do poço. A plantação de quiabo requer uma quantidade grande de água, por isso, ${ }^{6} \mathrm{~A}$ ramificação do poço é uma técnica desenvolvida pela comunidade do Assentamento Reunidas que consiste em fazer, com
tubos de ferro, alguns buracos na parede do poço para que ele verta mais água. A aplicação dessa técnica nos anos noventa poderia garantir um volume de água até dez vezes maior que o inicial. Para maiores detalhes ver ARBAROTTI, 2018. 
uma estratégia usada pelos assentados era fazer tanques que reservavam a água do poço e que eram posteriormente usadas para a irrigação.

Esses tanques, em sua grande maioria, eram construídos com máquinas da prefeitura, ou a partir do pagamento de alguém que possuía um trator para cavar o buraco, que posteriormente era recoberto com uma lona, para a água não infiltrar na terra. Entretanto, com a pouca disponibilidade hídrica dos poços, Seu João, bem como tantos outros que dependiam do poço para fazer a irrigação, tiveram que abandonar as culturas irrigadas. Assim, à medida que a seca aumentou e os poços passaram a secar, os agricultores que poderiam contar somente com o poço tiveram que mudar suas estratégias de produção, se reinventando, pois a água que abastecia o tanque de água já não era mais capaz de fazê-lo.

Cabe destacar, nesse contexto, que o processo de mudanças no clima do planeta, conforme é possível observar a partir da sensibilidade dos assentados, acaba por transformar não só os estilos e os modos de vida, mas provoca o apagamento de saberes e de técnicas. E isso ocorre na medida em que as técnicas tradicionais de produção passam a não mais surtir efeito a tendência é a busca de novas estratégias produtivas que muitas vezes podem não respeitarem seus modos de vida e suas relações históricas com a terra.

Este cenário, de uma terra e de uma vida mais seca, representa um reposicionamento nas estratégias produtivas, como dito, mas, também, leva muitos dos assentados a uma situação de maior vulnerabilidade e, por consequência, ao aumento nas desigualdades. Martins $(2008 ; 2013)$ chama atenção para esses elementos ao afirmar que as questões em torno do acesso a água devem ser consideradas para além do discurso de escassez e serem pensados no que tange aos usos práticos e significados culturais. As desigualdades de acesso a água, portanto, podem apontar para um processo de produção de diferenciações sociais e culturais entre os assentados e os grandes produtores, que possuem meios econômicos para acessarem água a partir de poços de grande profundidade.

Nesse sentido, como dizem Danowski e Viveiros de Castro (2014a; 2014b), as mudanças climáticas, têm como características de serem como um vírus, que no momento de uma crise maior atingirá a todos, ricos e pobres. Entretanto, é sabido que os primeiros e maiores impactados, diante de um cenário de crise, serão os pobres, "os condenados da terra", que receberão o status de excluídos socialmente, politicamente, economicamente e, também, ambientalmente.

\section{VIDA CAMPONESA EM TEMPOS DE INCERTEZAS}

As mudanças climáticas deixam marcas na terra e são sentidas no cotidiano, na paisagem e na produção. As mudanças climáticas tocam diretamente na estrutura de sentimentos dos agricultores, provocando insegurança ontológica, pois já não se pode contar com o companheiro clima. A mudança nos regimes de chuvas faz com que os agricultores se sintam perdidos no tempo. E, como bem destaca Elias (1998), a perda das referências espaço-temporais é decisiva nas estratégias e ordenamento da vida dos agentes.

Era uma tarde quente do atípico ano de 2015, que ainda assolava com uma forte seca os assentados. Conversando com Lara e Seu João sobre esta situação, a prosa tocou em um ponto que revela o quanto as mudanças no clima provocam um ambiente de sofrimento para muitas famílias de agricultores:

\section{Entrevistador: Esse poço dá quantos litros?}

Seu João: Esse dai tem... Estava com mais de 1 metro de água, por 1. Um metro de altura por 1,10 de...

Lara: Ramificou mais... Final do ano teve dia que ligou a bomba e não tinha mais água... Aí entrei em desespero, imagina..

Nesta fala observa-se que o poço que outrora vertia cerca de sete mil litros de água por hora, chegou a secar no auge da seca. O suposto de que o poço era uma fonte segura de água ficou no passado. Nem mesmo a técnica de ramificação permaneceu capaz de fazer o poço verter água. Nesse contexto, a certeza de que se poderia contar com a água do poço foi substituída pelo desespero da falta de água. E o desespero surge em situações inesperadas. A suspenção do cotidiano surge no momento em que um ato corriqueiro e feito muitas vezes sem pensar não surte mais efeito. Lara conta que surgiu o desespero no momento em que a bomba de água já não havia o que bombear. "Imagina uma vida sem água", questiona Lara, prevendo a possibilidade da necessidade da errância, experimentada, conhecida e retratada, como no romance Vidas Secas (RAMOS, 2008) e que faz parte da história de muitas famílias do Assentamento Reunidas. As mudanças climáticas já produzem seus desesperados (DANOWSKI; VIVEIROS DE CASTRO, 2014a). As mudanças climáticas já provocam muito medo, como pode ser visto na fala de Maria, 32 anos:

Entrevistador: Por conta dessa falta de chuva o pessoal que tem irrigação não teve problemas no ano passado? 
Maria: É, tiveram porque assim, o nível da água baixava muito rápido. Entrevistador: Do poço?

Maria: Tanto do poço, quanto do rio, baixava muito rápido, quem irrigava ali estava intercalando, umas duas vezes só por semana porque baixava muito a água, e não chovia, não chovia. E o medo, vai todo mundo ficar sem água.

E o medo! É o sentimento expressado por Maria ao relatar aquele contexto. Esta expressão é importante de ser cuidadosamente compreendida. Ela aparece depois do relato do desespero de perceber que a chuva não vinha. $O$ fato de a chuva não aparecer fez com que os agricultores passassem momentos de medo, incertezas e desespero. Olhar para o céu e não ver as nuvens de chuva passou a ser um pesadelo para estes agricultores, pois suas plantações estavam todas esturricadas, morrendo por falta de água e por causa do sol rigoroso.

$O$ medo! O medo tem como base a retirada das referências que até então faziam parte do cotidiano. O que será do futuro? Há futuro por vir? (DANOWSKI; VIVEIROS DE CASTRO, 2014a). O medo é a ausência de futuro. E se a chuva nunca mais cair? O medo da guerra leva pessoas a deixarem seus países, ou a pegarem em armas. O medo do clima já causou e ainda causa muitas migrações e imigrações. Muitos são os que passaram a ter medo do clima, o mesmo clima que outrora era um companheiro bem conhecido.

Não se constrói um futuro com medo, com insegurança, com incertezas. Como agir em um mundo incerto?, é a pertinente pergunta feita por Callon et all, (2001), para tentar entender um mundo onde a ciência e a política não conseguem mais dar boas respostas. "E o medo, vai ficar todo mundo sem água?", se perguntava Maria, angustiada a olhar para o céu em busca de um sinal de esperança em uma nuvem escura.

Mas, enfim, a água tombou dos céus, vindo de São Pedro, da procissão que lavou o cruzeiro com água, das promessas de Dona Catarina à Padim Cícero, ou porque simplesmente a chuva tinha mesmo que chegar em algum momento. Mas a experiência do medo deixa marcas na alma: quando o terror voltará, se perguntavam todos ressabiados? Como o clima é incompreensível, o que esperar do futuro? Como faremos para plantar? Em que mês lançar as sementes ao solo? Chegará o dia em que as chuvas não mais cairão do céu? Segundo Dona Aparecida essa é uma possibilidade plausível.

Dona Aparecida: (...) Eu acredito que Deus vai fazer isso, vai acabar tudo seco, porque tem tanta poluição e veneno no céu que a chuva não consegue cair do céu. Porque até hoje ninguém descobriu como que a chuva cai do céu, é um mistério.

O trauma surgido do medo produz pessoas inseguras, angustiadas e cheias de perguntas. As poucas ou quase nenhuma resposta causam ainda mais medo e insegurança, como pode-se notar na fala de Dona Aparecida, que baseada em suas crenças, formula uma ideia de futuro onde a chuva não mais cairá dos céus. Não cairá, pois existe muito veneno no céu, fruto da poluição humana.

Conforme indaga Tarde (2013) em seu ensaio Fragmentos de uma história futura, seremos obrigados a adentrar a terra e vivermos de minerais? Ou seguiremos para as estrelas, como no filme Interestelar, que retrata justamente um contexto climático que impede a produção agrícola (INTERESTELAR, 2014)? De fato, não há respostas, somente uma constatação: a de que as mudanças climáticas já produzem subjetividades voltadas ao medo e ao desespero. A constatação é de que as mudanças climáticas já alteraram as estratégias de vida e o modo de ser e estar no mundo dos assentados.

E isso pode ser percebido, pois são vários os relatos dos assentados que dão conta de que atualmente não é mais possível saber quando lançar as sementes ao chão. O clima, que antes era um companheiro fiel, com o qual podia-se contar, hoje é um desconhecido. O olhar para o céu do agricultor, hoje, é com desconfiança. O que resta, nesse contexto é buscar um ponto de apoio, uma esperança na tradição religiosa, como mostra Seu Luiz, 67 anos: "Rapaz, olha, sinceramente, eu vou falar pra você, tudo depende daquele Homem que tá lá em cima [Deus], porque se ele não mandar chuva, pode plantar do jeito que você plantar, se não tiver a chuva... Quem produz com um sol desse, moço?"

Dentro do universo simbólico da cosmologia religiosa que perpassa a cultura dos assentados, uma boa plantação está ligada $\grave{a}$ vontade e $a ̀$ graça divina, pois, segundo a fala de Seu Luiz, quem faz chover, ou melhor, "manda a chuva", é uma entidade que está fora do alcance dos agricultores. A fala anterior de Dona Aparecida também tocava nesse tema, ao dizer que ninguém sabe como faz chover. A chuva, portanto, é um mistério reservado à divindade e um elemento central no processo produtivo e no universo sociocultural dos assentados, visto que é ela que garante uma boa produção e abastece os poços que garantem a água para a casa e para a irrigação.

Outrossim, a propósito das cosmologias religiosas que tentam dar um alívio às angustias causadas pelas mudanças climáticas, vale trazer a fala de Dona Catarina, 81 anos, que diz que as mudanças no clima acontecem por conta da própria ambição 
do ser humano.

Dona Catarina: É menino, só sei dizer que está escrito na palavra, o dia que os homens quiserem mexer no tempo Deus ia mudar o tempo. E é o que está acontecendo. As plantas estão tudo mudada. O tempo, o tempo está tudo mudado que a gente não sabe quando é que chove e quando que não chove. Quando planta e quando não planta...

\section{Entrevistador: E a senhora acha que vai melhorar ou piorar isso?}

Dona Catarina: Só vai é piorar! E você não sabe da história de Sodoma e Gomorra? Deus mandou um anjo para achar dez justos que fosse e o anjo não achou. E mandou outra vez. Até que sobrou só uma família e pronto, Deus acabou com a cidade todinha. Eé isso que vai acontecer. Deus está mandando sinal, mas a gente não respeita. Ai o que vai acontecer?

Como visto, os assentados já sentem alterações no sistema climático do planeta. E os sinais aos quais Dona Catarina se refere são os impactos experimentados pelos agricultores em suas vidas cotidianas. O homem mexer no tempo, leia-se aqui, no clima, remete-se a todas as interferências humanas no que, para Dona Catarina, e tantos outros assentados, é criação e a obra de Deus. E o castigo de Deus, dentro desta chave de leitura do mundo, é a transformação de todo esse sistema climático, o que levaria e tem levado o ser humano a muitas dificuldades.

Dona Catarina afirma ainda que esse cenário vai se tornar cada vez mais difícil, se mostrando pessimista quanto ao futuro. E para mostrar esse pessimismo uma passagem bíblica é mobilizada para expressar o seu sentimento em relação ao futuro e esse sentimento é de que assim como Deus destruiu a cidade de Sodoma e Gomorra, Ele destruirá o planeta. "E é isso que vai acontecer", diz ela. Com essas palavras é possível perceber que, assim como Dona Aparecida, as expectativas de futuro além de serem incertas, elas se anunciam catastróficas.

As duas falas precedentes mostram que esse é o resultado da relação estabelecida entre homem e mulher e natureza na era capitalista industrial. E como apontou Willians (2011), a maneira como tratamos a nossa relação com a natureza está nos conduzindo a uma realidade de consequências imprevisíveis e, ainda, em grande medida, negligenciadas. Entretanto, é possível perceber que existem populações que já percebem os efeitos dessa relação predadora com a natureza, resultado de um modo de produção e modelo econômico, que não escapa aos olhos de Dona Júlia, 67 anos. Um modelo que apaga a diversidade de experiências em prol de uma experiência sintética e técnica, a semente da Monsanto, versus as sementes crioulas, tradicionais e plurais.

\section{Entrevistador: A senhora tem percebido uma mudança no clima?}

Dona Júlia: Sem dúvida mudou e muito, se não, não tava aí o povo tudo doente. Essa mudança de clima somos nós que somos culpado, né filho, infelizmente. A cabeça do povo, o capitalismo, ele tem uma estratégia de mudar a mente. Que nem o transgênico, a Monsanto, essas outras indústrias, eles já produz essas semente pra depender do agrotóxico, uma coisa puxa a outra. Se você vai modificar as sementes, mas precisa do adubo, do veneno, tá entendendo? A não ser que, onde você vai achar uma semente crioula hoje? Não tem!

A fala de Dona Julia traz alguns pontos que podem ser tomados como o resumo dos problemas enfrentados dentro deste contexto de alterações no clima discutidos até aqui. A sua percepção das mudanças climáticas está ligada ao aumento no número de doenças, a tecnificação, à perda de sementes tradicionais e à dependência da agricultura de agrotóxicos e adubos químicos dentro de um modelo de economia capitalista. Como ela mesmo disse, uma coisa puxa a outra, ou seja, um sistema interligado que causa danos ao planeta e as pessoas. E na sua leitura, os culpados somos todos nós, ou seja, as mudanças não são resultado de algo sobrenatural, mas sim da ação humana. Essa fala é importante por dois motivos.

Primeiro, ela mostra que a interpretação feita pelos assentados das mudanças climáticas não se restringem somente aos elementos religiosos. De fato, existe uma leitura de mundo, por parte dos assentados, que sabem identificar as questões econômicas e sociais que estão envolvidas nesse processo de degradação do planeta. O discurso religioso, nesse sentido, deve ser lido como uma expressão discursiva entremeada de componentes políticos, sociais e econômicos que compõem a percepção das mudanças climáticas.

Segundo, ao dizer que "nós que somos culpado", Dona Julia assume sua parte na culpa. E é importante que todos assumamos nossa parcela na catástrofe do clima, pois o limite do respeito foi ultrapassado. Todavia, não se pode eximir de culpa maior os que contribuem de forma mais decisiva para que vivamos em um período de ausência de futuro ou em um futuro "cada vez pior". Stengers (2013; 
2015) nomeia de "nossos responsáveis" a estes que deve-se colocar a maior parte da culpa pelas mudanças climáticas. Esses responsáveis, em grande medida, surgem da articulação entre política e ciência. Ou, como na nomeação de Callon et All (2001), esses são os "responsáveis políticos". Pensando sobre esse ponto, Anders (2007) será ainda mais radical do que essas proposições ao dizer que a humanidade, no caso dos meios que produzem os tempos ausentes de futuro, está dividida entre aqueles que são os culpados e os que são vítimas. Para o autor, é falso pensar que esse momento histórico é resultado da ação de todos os homens, pois são as decisões político-econômicas de parte da humanidade que provocou essa situação.

Essa dualidade, portanto, não é mobilizada somente para retirar a responsabilidade de parte das pessoas, mas sim como um instrumento de reação: "Temos que ter em conta essa dualidade na nossa reação: nosso trabalho tem por nome "combate"" (ANDERS, 2007, p.33. Tradução nossa) ${ }^{7}$. Para Anders (2007), portanto, essa dualidade é um instrumento político de ação, visto que a concretização da sensação de ausência de futuro produzirá uma única humanidade vencida. Isso é, o fim da humanidade ou o fim do mundo.

É nessa mesma esteia que Michael Foessel (2012), afirma que a constatação e a formulação de discursos sobre o fim do mundo devem ultrapassar os sentimentos de angústia, medo e de falta de lugar no mundo para a ocupação de espaços de ação para pensar a fundação de uma nova ordem cosmopolita. Os elementos que formam, portanto, a interpretação da existência social dos assentados mesclando a constatação das alterações no clima com angústias acerca da vida futura, quer passando por leituras religiosas, quer por constatações socioeconômicas, podem ser a base para a construção de uma nova ordem social.

\section{OBSERVAÇões Finais (OU EM BUSCA DE UM LUGAR NO MUNDO)}

Para sair da simples constatação do eminente desastre, Anders (2007) procura uma alternativa ao afirmar que as antigas gerações não poderiam ter percebido o tamanho do problema em que estávamos inseridos e as próximas gerações, talvez, não terão oportunidade de transformação, pois é muito provável que seja tarde demais. Por isso, para o referido autor, diferente dos apocalipistas judeus e cristãos que esperam e sonham com o apocalipse que irá estabelecer o reino da paz e harmonia, o objetivo da geração presente é o de impedir o apocalipse, pois o que nos aguarda não é algo positivo, mas sim uma ameaça real em meio ao cotidiano da técnica, que poderá por fim a experiência humana no planeta.

Nossa geração é apocalipistas por uma questão de erro e, assim, para continuarmos a gozar da existência do ser é imprescindível frear o apocalipse com uma resposta tão real quanto a ameaça. A conservação do mundo, portanto, só será possível em um mundo diferente do atual, por isso a única certeza que deve guiar as ações humanas é que temos que correr mais rápido que as gerações anteriores e mais rápidos que o curso do próprio tempo para mitigar "o tempo do fim” (ANDERS, 2007).

E partir da constatação dos problemas para pensar as possibilidades é algo incontornável, segundo Benjamin (2012), pois somente a partir do momento em que são identificados os princípios que fundamentam a tradição cultural da dominação, para saber dizer os horrores e as destruições, é que se torna possível trazer a tona outras possibilidades de vidas vividas, de relação com a natureza e de ser e estar no mundo. Assim, para Leff $(2005,2010)$, ao se elaborar críticas ao modelo de racionalidade e de produção hegemônicos, é importante propor a construção de outro modelo, que seja baseado em uma racionalidade ambiental e que leve em consideração as dependências e as diferentes formas de indeterminação na relação sociedade e natureza. Essa proposta aponta para um conceito de socialismo e racionalidade ambiental, diante do totalitarismo político e científico, que se funde na “[...] apropriação social e na gestão democrática e participativa do ambiente, concebido este como um sistema de recursos, de meios de produção, de potenciais produtivos e de condições de existência" (LEFF, 2010, p.126).

O que é também ponderado por Marcuse (1973), ao afirmar que só é possível construir uma alternativa ao modelo hegemônico da ciência e da técnica desde que surja resistência por parte das populações onde o processo de industrialização e introdução de tecnologias ainda não ocorreu ou não se consolidou. Como, por exemplo, no Assentamento, que vive uma realidade no entremeio da tradição e do modelo hegemônico, e que, por isso, tem a potencialidade de mostrar alternativas criativas ao modelo puro. Essa proposta seria a de realizar uma política planejada que não sobreporia a industrialização e a tecnologia hegemônicas aos estilos de vida, trabalho e modo de produção dessas comunidades, mas colocaria essas bases técnicas para ampliar e melhorar as bases já existentes. Garantindo, assim, o desenvolvimento de uma existência humana integrada a natureza e respeitando todos os viventes, quebrando, definitivamente, a redoma que separa e eleva as pessoas acima da natureza (DANOWSKI; VIEIROS DE CASTRO, 2014b).

Assim, pensando em ações concretas, Jollivet (2015) afirma que diante de um futuro pleno de incertezas, o mínimo que temos a fazer é pensar sobre um novo modelo de sociedade, um modelo cidadão, e ter esse modelo como algo a seguir. Um modelo que, segundo o autor, supere a noção dos Estados Nacionais, visto que as mudanças climáticas não podem ser retidas nas fronteiras dos países. É 
necessário, portanto, pensar soluções dentro de uma chave político social que compreenda a relação da vida das espécies como um todo. Segundo Ceceña (2013) a alternativa passaria pela constituição de Territórios da natureza como o primeiro caminho para pensar uma mudança civilizacional onde a "Madre Tierra" voltaria a ser sujeito da história.

Essas propostas significariam um pacto de paz com o planeta Terra e a formulação de uma proposta de vida mais lenta (desacelerada), como diria Stengers (2013; 2015), fugindo do crescimento a todo custo do capitalismo financeiro e criando uma possibilidade de futuro que não seja a barbárie. $O$ mal estar causado pelas mudanças climáticas em nossas vidas é, de fato, um chamado à resistência a esse modelo de crescimento a todo custo. Um modelo no qual nós estamos compreendidos, o que significa uma luta contra nós mesmos. Uma luta que significa

[...] criar uma vida "depois do crescimento", uma vida que explore as conexões com novas potencias de agir, sentir, imaginar e pensar (...) de aprender concretamente a reinventar modos de produção e de cooperação que escapem as evidências de crescimento e de competição (STENGERS, 2013, p. 14. Tradução nossa) ${ }^{8}$.

E justamente por isso Ceceña (2013) defende a necessidade de uma refundação do mundo por meio de uma profunda transformação cultural, onde possam surgir visões de mundo não capitalistas. Isso implicaria mais que uma tomada de governo, mas sim a geração de uma cultura de mundo em que caibam todos os mundos ("mundo-en-el-que-caben-todos-los-mundos").

Também Danowski e Viveiros de Castro (2014b) chamam atenção para a necessidade de fugir desse modelo capitalista baseado no crescimento e desenvolvimento para escapar dos dramas sociais e ambientais atuais. Para os autores, portanto, é necessário deslocar esse conceito de desenvolvimento e crescimento a todo custo dirigindo os olhares para os países superdesenvolvidos ou excessivamente desenvolvidos. Os Estados Unidos, com seu modelo "American way of life", é a expressão máxima desse superdesenvovimento, consumindo quatro vezes mais que o restante da população do planeta, ou seja, "há gente de menos com mundo demais e gente demais com mundo de menos" (DANOWSKI; VIVEIROS DE CASTRO, 2014a, p.129).

A ideia, assim, consistiria em elaborar um fundamento econômico cujo objetivo

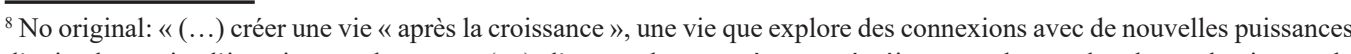
d'agir, de sentir, d'imaginer et de penser (...) d'apprendre concrètement à réinventer des modes de production et de coopération qui échappent aux évidences de la croissance et de la compétition ».

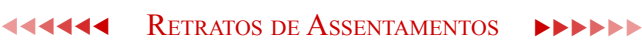

v.22, n.1, 2019 principal seria efetuar a distribuição da riqueza existente e não, somente, em produção de riqueza. Essa "des-economia", ou simplesmente a partilha do que é produzido levando em conta todos os viventes, segundo os autores, além de provocar uma libertação no que tange ao crescimento econômico contínuo, provocaria uma certa insurreição cultural no processo de "zumbificação do cidadão-consumidor". Cidadão-consumidor que tem incutido em sua existência certa angústia que faz os luxos de ontem se tornarem as necessidades de hoje. Assim, esse deslocamento permitiria trazer à tona um modelo de desenvolvimento não ligado estritamente ao binômio: crescimento econômico igual à saída da pobreza.

Stengers (2013) possui uma posição mais radical diante dessa proposta de Danowski e Viveiros de Castro (2014a) ao lançar a noção de "Slow Science". Para autora, diante da barbárie anunciada urge a aceleração da desaceleração das ciências e da civilização. Vendo a ciência como uma das bases do processo de desenvolvimento e crescimento, a chave alternativa seria diminuir de forma rápida todos os ritmos. Esse movimento "slow" na ciência e em vários outros setores, para a autora, tem a capacidade de refutar a racionalidade do capitalismo.

Deste modo, a alternativa mostra-se para Danowski e Viveiros de Castro (2014a, 2014b), a partir da organização social das comunidades do mundo que ainda conservam uma relação com o mundo material em outros moldes - onde o Estado é dispensado, a terra é vista como parte integrante da vida social e tida como local de onde emana a autonomia política, econômica e social, a despeito da megamáquina do capitalismo de consumo e da produção 24 horas por dia. Sociedades que não se preocupam com a possibilidade de um futuro melhor, mas que se baseiam no presente, e tentam fazer dele o melhor possível.

Nesse sentido, Ceceña (2013) defende que os povos Mesoamericanos, Mayas e outros têm muito a contribuir a respeito da recuperação de modos alternativos e mais comunitários de organização, em que estão incluídos geografia, natureza e cosmos. Para a autora, esses elementos clamam para uma transformação radical da vida em que a "Madre Tierra" não é vista como nossa, mas sim que nós pertencemos ao planeta.

As profecias do fim do mundo, neste sentido, são anunciadas para que haja uma possibilidade de que elas não ocorram. Identificar os grupos sociais que já sofrem com as mudanças climáticas, servem para pensar caminhos para que elas parem. A palavra de ordem, portanto, é de que temos o dever de sermos pessimistas. Essa é a única via, segundo Danowski e Viveiros de Castro (2014a, p.115) citando Anders, de se fazer "[...] um combate travado no 'tempo do fim' para recuar 'o fim dos tempos". Isso porque, continuam os autores, "falar no fim do mundo é falar da 
necessidade de imaginar, antes que um novo mundo em lugar deste nosso mundo presente, um novo povo; o povo que falta" (p.159). Em outras palavras, como estava grafitado na entrada da Universidade de Paris X, como sendo um lema de esperança a se seguir: "Um outro fim do mundo é possivel".

\section{REFERÊNCIAS}

ANDERS, G. Les temps de la fin. Paris: L'Herne, 2007.

ARBAROTTI, A. E. Disputas e hierarquias no acesso à água em assentamentos de reforma agrária. Tese (Doutorado em Sociologia). São Carlos: UFSCar, 2018.

BENJAMIM, W. Charles Baudeleire: um lírico no auge do capitalismo. $1^{\text {a }}$. Ed. São Paulo; Brasiliense, 1989. (Obras escolhidas v.3)

Magia e técnica, arte e política: ensaios sobre literatura e história da $\overline{\text { cultura. }} 8^{\text {a }}$. Ed. São Paulo: Brasiliense, 2012. (Obras escolhidas v.1)

BORGES, M. S. L. Terra. Ponto de partida, ponto de chegada: Identidade e luta pela terra. São Paulo: Anita, 1997.

CALLON, M. LASCOUMES, P. BARTHE, Y. Agir dans un monde incertain : essai sur la démocratie technique, 2001.

CECEÑA, A. E. La Madre tierra como sujeito de la historia. Observatório Latino Americano de Geopolítica. Revista ALASRU, 2013. Disponível em: http://www. geopolitica.ws/media/uploads/alasru.pdf

DANOWSKI, D. VIVEIROS DE CASTRO, E. Há mundo por vir? Ensaios sobre os medos e os fins. Florianópolis: Cultura e Barbárie, 2014a.

Diálogos sobre ofim do mundo. Entrevista. Jornal El País, 2014b. Disponível em: http://brasil.elpais.com/brasil/2014/09/29/opinion/1412000283_365191.html ELIAS, N. Sobre o tempo. Rio de Janeiro: Jorge Zahar, 1998.

FOESSEL, M. Après la fin du monde : critique de la raison apocalyptique. Paris : SEUIL, 2012.
G1 NATUREZA. "Será que estamos entrando na sexta grande extinção?”, diz brasileira sore estudo da ONU de espécies ameaçadas, 2019. Disponível em https://g1.globo.com/natureza/noticia/2019/05/06/sera-que-estamos-entrando-nasexta-grande-extincao-diz-brasileira-sobre-estudo-da-onu-de-especies-ameacadas. ghtml

HALBWACHS, M. A memória coletiva. São Paulo: Centauro, 2006.

HARARI, Y. N. Homo Deus: uma breve história do amanhã. São Paulo: Companhia das letras, 2016.

INTERESTELAR. Direção: Christopher Nolan: Warner Bros Pictures, 2014.

JOLLIVET, M. Pour une transition écologique citoyenne. Paris : Charles Léopold Mayer, 2015.

LEFF, E. Ecología y capital: racionalidad ambiental, democracia participative y desarrollo sustentable. México: Siglo Veintiuno Editores, 2005.

Epistemologia ambiental. 5. ed. São Paulo: Cortez, 2010.

MARCUSE, H. A ideologia da sociedade industrial. O homem unidimensional. Rio de Janeiro: Zahar Ed. 1973.

MARTINS, R. C. Sociologia da governança francesa das águas. Revista Brasileira de Ciências Sociais, v. 23, p. 83-100, 2008.

. A construção social da economia política da água. Sociologia (Lisboa), v. 2013, p. 111-130, 2013.

NORDER, L. A. C. Políticas de Assentamento e localidade: os desafios da reconstituição do trabalho rural no Brasil. 2004.

PIMM, S. L. et all. The biodiversity of species and their rates of extinction, distribution, and protection. Revista Science Vol. 334, Issue 6187,1246752, 2014.

RAMOS, G. Vidas secas. Rio de Janeiro: Record, 2008. 
STENGERS, I. Au temps des catastrophes : résister à la barbarie qui vient. Paris : La Découverte, 2013.

"Le prix du progrès" : discussion avec Isabelle Stengers sur les sorcières néopaïennes et la science moderne. Revista Jef Klak(on line). Abril, 2015.

TARDE, G. Fragmentos de história futura. Florianópolis: Cultura e Barbárie, 2013.

WILLIAMS, R. Cultura e materialismo. São Paulo: Unesp, 2011.
Revista Retratos de Assentamentos

Vol. 22 N.1 de 2019 ISSN: 1516-8182

Recebimento: 03/07/2018 Aceite: 07/09/2018

DOI: $10.25059 / 2527-2594 /$ retratosdeassentamentos/2019.v22i1.330

\section{Estudo exploratório sobre dinâmica do desmatamento em assentamentos localizados no território portal da Amazônia} Mario Ávila osé Vicente Elias Bernard Antônio Felipe Couto Júnior ${ }^{4}$

RESUmo: Os assentamentos na Amazônia são fundamentais para a distribuição de terras, porém sua implementação ainda traz muitos problemas ambientais e sociais, o que tem levado a críticas sobre as condições de sustentabilidade dos mesmos e avaliar o impacto ambiental ocasionado por este grupo local, está se tornando um dos empregos mais frequentes da utilização de indicadores. O objetivo deste texto então, foi caracterizar de maneira exploratória, a dinâmica do desmatamento em assentamentos localizados no Território Portal da Amazônia, localizado no norte do estado do Mato Grosso utilizando indicadores extraídos do IBGE, IMAZON e INPE. Neste estudo, os assentamentos que respondem por parcelas significativas de desmatamento estão nos municípios de Guarantã do Norte, Novo Mundo e Peixoto de Azevedo estando evidente a dinâmica de desmatamento ocasionado pela ocupação para pastagens, criação de bovinos seguido de culturas anuais (soja) em regiões selecionadas e migração para novas áreas para reiniciar o ciclo apresentado. Entender a dinâmica do desmatamento nos assentamentos localizados no Território Portal da Amazônia é essencial para que se busque implementar talvez, um modelo mais sustentável - capaz de conciliar a conservação da floresta e ainda melhorar a condição de vida dos assentados - bem como reduzir conflitos e pobreza rural.

PalaVras-chaVe: Desmatamento; assentamentos de reforma agraria; Mato Grosso.

ABSTRACT: The Amazon settlements are fundamental for land distribution, but its implementation still brings many environmental and social problems, which has been criticized about its sustainability conditions. Evaluate the environmental impact caused by this local group, is becoming one of the most frequent jobs in the use of indicators. The objective of this text was to characterize in an exploratory way, the dynamics of deforestation in settlements located in the Territorio Portal da Amazonia, located in the north of the state of Mato Grosso using indicators extracted from IBGE, IMAZON and INPE. In this study, the settlements that account for significant portions of deforestation are in the municipalities of Guarantã do Norte, Novo Mundo and Peixoto de Azevedo being evident the dynamics of deforestation caused by the occupation for pastures, livestock breeding followed by annual crops (soybean) in selected regions and migration to new areas. Understanding

'Doutoranda em Ciencias ambientais - PPGCA/UnB. E-mail: silassad@gmail.com

${ }^{2}$ Doutor em Desenvolvimento Sustentavel - CDS/UnB. E-mail: unbavila@gmail.com

${ }^{3}$ Docentte do Programa de Pós-Graduação Interunidades (CENA-ESALQ) em Ecologia Aplicada, USP. E-mail: vicente. bernardi@yahoo.com.br

'Doutor em Geociências Aplicadas (2012) pelo Instituto de Geociências da Universidade de Brasília (UnB).E-mail: afcj@ unb.br 